\title{
Phase I study of the gamma secretase inhibitor PF-03084014 in combination with docetaxel in patients with advanced triple- negative breast cancer
}

\author{
Marzia A. Locatelli' ${ }^{1}$, Philippe Aftimos ${ }^{2}$, E. Claire Dees ${ }^{3}$, Patricia M. LoRusso ${ }^{4,9}$, Mark \\ D. Pegram ${ }^{5}$, Ahmad Awada ${ }^{2}$, Bo Huang ${ }^{6}$, Rossano Cesari7, Yuqiu Jiang8, M. Naveed \\ Shaik $^{8}$, Kenneth A. Kern ${ }^{8}$ and Giuseppe Curigliano ${ }^{1}$ \\ ${ }^{1}$ Division of Experimental Therapeutics, European Institute of Oncology, Milan, Italy \\ ${ }^{2}$ Medical Oncology Clinic, Institut Jules Bordet, Université Libre de Bruxelles, Brussels, Belgium \\ ${ }^{3}$ Department of Hematology and Oncology, University of North Carolina, Lineberger Comprehensive Cancer Center, Chapel \\ Hill, NC, USA \\ ${ }^{4}$ Medical Oncology, Karmanos Cancer Institute, Detroit, MI, USA \\ ${ }^{5}$ Breast Cancer Research Program, Stanford Cancer Institute, Stanford, CA, USA \\ ${ }^{6}$ Pfizer Oncology, Groton, CT, USA \\ ${ }^{7}$ Pfizer Oncology, Milan, Italy \\ ${ }^{8}$ Pfizer Oncology, San Diego, CA, USA \\ ${ }^{9}$ Yale Cancer Center, New Haven, CT, USA \\ Correspondence to: Giuseppe Curigliano, email: giuseppe.curigliano@ieo.it
}

Keywords: breast cancer, triple-negative, PF-03084014, gamma secretase, NOTCH signaling

Received: July 25, $2016 \quad$ Accepted: November 22, $2016 \quad$ Published: November 30, 2016

\section{ABSTRACT}

Background: The NOTCH signaling pathway may be involved in the survival of stem cell-like tumor-initiating cells and contribute to tumor growth. In this phase Ib, open-label, multicenter study (NCT01876251), we evaluated PF-03084014, a selective gamma-secretase inhibitor in patients with advanced triple-negative breast cancer.

Methods: The dose-finding part was based on a $2 \times 3$ matrix design using the modified toxicity probability interval method. Oral PF-03084014 was administered twice daily continuously in combination with intravenous docetaxel given on day 1 of each 21-day cycle. Primary endpoint was first-cycle dose-limiting toxicity (DLT) for the dose-finding part and 6-month progression-free survival (PFS) for the expansion cohort treated at the maximum tolerated dose (MTD). Secondary endpoints included safety, objective response, and pharmacokinetics of the combination.

Results and Conclusions: The MTD was estimated to be PF-03084014 $100 \mathrm{mg}$ twice daily / docetaxel $75 \mathrm{mg} / \mathrm{m}^{2}$. At this dose level, combination treatment was generally well tolerated (one DLT, grade 3 diarrhea, among eight DLT-evaluable patients). The most common all-grade, treatment-related adverse events reported in all patients $(\mathrm{N}$ $=29$ ) were neutropenia $(90 \%)$, fatigue $(79 \%)$, nausea $(72 \%)$, leukopenia $(69 \%)$, diarrhea (59\%), alopecia (55\%), anemia (55\%), and vomiting (48\%). No effect was observed on the pharmacokinetics of docetaxel when administered in combination with PF-03084014. Four (16\%) of 25 response-evaluable patients achieved a confirmed partial response; nine $(36 \%)$ patients had stable disease, including five patients with unconfirmed partial response. In the expansion cohort, median PFS was 4.1 (95\% CI 1.3-8.1) months (6-month PFS rate $17.1 \%$ [95\% CI 0.8-52.6\%]).

\section{INTRODUCTION}

Triple-negative breast cancer (TNBC) is defined by the lack of estrogen (ER), progesterone (PR), and human epidermal growth factor 2 (HER2) receptors, and it accounts for approximately $15 \%$ of all breast cancer cases. Metastatic TNBC (mTNBC) is associated with a poor prognosis [1-3]. TNBCs represent a heterogeneous group 
Table 1: Patient baseline characteristics

\begin{tabular}{|c|c|c|c|c|}
\hline Characteristic & $\begin{array}{l}\mathrm{PF}-03084014 \quad 100 \quad \mathrm{mg} \\
\mathrm{BID} / \\
\text { docetaxel } 75 \mathrm{mg} / \mathrm{m}^{2} \\
(n=15)\end{array}$ & $\begin{array}{l}\text { PF-03084014 } 100 \mathrm{mg} \text { BID/ } \\
\text { docetaxel } 100 \mathrm{mg} / \mathrm{m}^{2} \\
(n=3)\end{array}$ & $\begin{array}{l}\mathrm{PF}-03084014150 \mathrm{mg} \mathrm{BID} / \\
\text { docetaxel } 75 \mathrm{mg} / \mathrm{m}^{2} \\
(n=11)\end{array}$ & $\begin{array}{l}\text { All dose levels } \\
(N=29)\end{array}$ \\
\hline Mean (range) age, years & $53(34-76)$ & $43(32-64)$ & $46(27-69)$ & $50(27-76)$ \\
\hline $\begin{array}{l}\text { Race, } n(\%) \\
\text { White } \\
\text { Black }\end{array}$ & $\begin{array}{c}14(93) \\
1(7)\end{array}$ & $\begin{array}{c}3(100) \\
0\end{array}$ & $\begin{array}{c}11(100) \\
0\end{array}$ & $\begin{array}{c}28(97) \\
1(3)\end{array}$ \\
\hline $\begin{array}{l}\text { ECOG PS, } n(\%) \\
0 \\
1 \\
\end{array}$ & $\begin{array}{l}9(60) \\
6(40) \\
\end{array}$ & $\begin{array}{l}1(33) \\
2(67) \\
\end{array}$ & $\begin{array}{l}8(73) \\
3(27) \\
\end{array}$ & $\begin{array}{l}18(62) \\
11(38) \\
\end{array}$ \\
\hline $\begin{array}{l}\text { Disease, } n(\%) \\
\text { Metastatic } \\
\text { Locally recurrent } \\
\end{array}$ & $\begin{array}{c}14(93) \\
1(7) \\
\end{array}$ & $\begin{array}{c}3(100) \\
0 \\
\end{array}$ & $\begin{array}{l}8(73) \\
3(27) \\
\end{array}$ & $\begin{array}{c}25(86) \\
4(14) \\
\end{array}$ \\
\hline Prior cancer surgery, $n(\%)$ & $15(100)$ & $3(100)$ & $11(100)$ & $29(100)$ \\
\hline $\begin{array}{l}\text { Prior systemic treatment }{ }^{\mathrm{a}}, n(\%) \\
\text { No } \\
\text { Yes }\end{array}$ & $\begin{array}{c}10(67) \\
5(33) \\
\end{array}$ & $\begin{array}{c}3(100) \\
0 \\
\end{array}$ & $\begin{array}{l}7(64) \\
4(36) \\
\end{array}$ & $\begin{array}{c}20(69) \\
9(31) \\
\end{array}$ \\
\hline $\begin{array}{l}\text { Prior radiation therapy }{ }^{\mathrm{a}}, n(\%) \\
\text { No } \\
\text { Yes }\end{array}$ & $\begin{array}{c}11(73) \\
4(27) \\
\end{array}$ & $\begin{array}{c}3(100) \\
0 \\
\end{array}$ & $\begin{array}{l}9(82) \\
2(18) \\
\end{array}$ & $\begin{array}{c}23(79) \\
6(21) \\
\end{array}$ \\
\hline $\begin{array}{l}\text { Prior taxane therapy, } n(\%) \\
\text { Yes (adjuvant) } \\
\text { Yes (neoadjuvant) } \\
\text { Yes (advanced) }\end{array}$ & $\begin{array}{c}6(40) \\
4(27) \\
0\end{array}$ & $\begin{array}{c}1(33) \\
0 \\
0\end{array}$ & $\begin{array}{c}4(36) \\
1(9) \\
0\end{array}$ & $\begin{array}{c}11(38) \\
5(17) \\
0\end{array}$ \\
\hline
\end{tabular}

ECOG PS, Eastern Cooperative Oncology Group performance status.

aprior anticancer treatment in the advanced/metastatic setting.

of tumors with one common clinical feature: a distinctly aggressive nature with higher rates of relapse and shorter overall survival in the metastatic setting compared with other breast cancer subtypes. Because of the absence of well-defined molecular targets, cytotoxic chemotherapy is currently the standard treatment option for TNBC. Progression on first-line taxane therapy often occurs relatively early in $\mathrm{mTNBC}$, with a median progression-free survival (PFS) of about 5-6 months [1-3]. Gene expression profiling identified six TNBC subtypes displaying unique gene expression and ontologies, including two basal-like, an immunomodulatory, a mesenchymal, a mesenchymal stem-like, and a luminal androgen receptor subtype [4].

It has been hypothesized that the poor response to standard treatment seen in patients with TNBC may be related to the presence of stem cell-like tumor-initiating cells refractory to cytotoxic chemotherapy $[3,5,6]$. The NOTCH signaling pathway is involved in the survival of stem cell-like tumor-initiating cells, as it plays an important role in normal stem cell development and differentiation, tumor growth regulation, and malignant cell survival [7-11]. Upregulation of the NOTCH pathway occurs in mesenchymal and mesenchymal stem-like TNBCs. Further, high levels of NOTCH and JAG1 were detected in tumors with poor-prognosis features and found associated with shorter survival compared to breast cancer patients with low tumor levels of NOTCH1 and JAG1 [79].
PF-03084014 is a reversible, noncompetitive, selective gamma-secretase inhibitor that blocks the NOTCH signaling pathway. It has demonstrated antitumor activity in preclinical xenografts models and in patients with solid tumors, including advanced thyroid cancer and desmoid tumors, and T-cell acute lymphoblastic leukemia [12-15]. Combination of PF-03084014 with docetaxel significantly increased inhibition of tumor growth in patient-derived and cell-line xenograft models of TNBC [13], prompting evaluation of this combination for the treatment of patients with TNBC.

This phase I study (A8641016) was designed to estimate the maximum tolerated dose (MTD) of PF03084014 in combination with docetaxel, and evaluate safety, tolerability, pharmacokinetics, and antitumor activity in patients with advanced TNBC.

\section{RESULTS}

\section{Patients}

Twenty-two patients with mTNBC or hormonerefractory ER/PR-receptor positive breast cancer (two $\mathrm{ER}+$ and one $\mathrm{PR}+$ ), who had received up to two lines of prior therapy in the metastatic setting, were treated during dose escalation at three dose levels: eight at dose $2 \mathrm{~b}$ (PF- 
Table 2: Treatment-related adverse events occurring in more than $20 \%$ of patients $(N=29)^{\mathrm{a}}$

\begin{tabular}{|c|c|c|c|c|c|}
\hline Adverse event & $\begin{array}{c}\text { Grade } 1 \\
n(\%)\end{array}$ & $\begin{array}{c}\text { Grade } 2 \\
n(\%)\end{array}$ & $\begin{array}{c}\text { Grade 3b } \\
n(\%)\end{array}$ & $\begin{array}{c}\text { Grade } 4 \\
n(\%)\end{array}$ & $\begin{array}{c}\text { All grades } \\
\boldsymbol{n}(\%)\end{array}$ \\
\hline Neutropeniac & 0 & $1(3)$ & $1(3)$ & $24(83)$ & $26(90)$ \\
\hline Fatigue & $6(21)$ & $15(52)$ & $2(7)$ & 0 & $23(79)$ \\
\hline Nausea & $12(41)$ & $7(24)$ & $2(7)$ & 0 & $21(72)$ \\
\hline Leukopenia $^{\mathrm{d}}$ & 0 & $1(3)$ & $13(45)$ & $6(21)$ & $20(69)$ \\
\hline Diarrhea & $5(17)$ & $9(31)$ & $3(10)$ & 0 & $17(59)$ \\
\hline Alopecia & $9(31)$ & $7(24)$ & 0 & 0 & $16(55)$ \\
\hline Anemia & $7(24)$ & $8(28)$ & $1(3)$ & 0 & $16(55)$ \\
\hline Vomiting & $9(31)$ & $4(14)$ & $1(3)$ & 0 & $14(48)$ \\
\hline Mucosal inflammation & $8(28)$ & $4(14)$ & $1(3)$ & 0 & $13(45)$ \\
\hline $\operatorname{Rash}^{\mathrm{e}}$ & $8(28)$ & $5(17.2)$ & 0 & 0 & $13(45)$ \\
\hline Hypophosphatemia & $3(10)$ & $4(14)$ & $4(14)$ & 0 & $11(38)$ \\
\hline Febrile neutropenia & 0 & 0 & $2(7)$ & $6(21)$ & $8(28)$ \\
\hline Thrombocytopenia $^{\mathrm{f}}$ & $5(17)$ & $4(14)$ & 0 & 0 & $9(31)$ \\
\hline Pyrexia & $7(24)$ & 0 & 0 & 0 & $7(24)$ \\
\hline Stomatitis & $3(10)$ & $4(14)$ & 0 & 0 & $7(24)$ \\
\hline Constipation & $5(17)$ & $1(3)$ & 0 & 0 & $6(21)$ \\
\hline Decreased appetite & $2(7)$ & $4(14)$ & 0 & 0 & $6(21)$ \\
\hline Headache & $5(17)$ & $1(3)$ & 0 & 0 & $6(21)$ \\
\hline Proteinuria & $2(7)$ & $4(14)$ & 0 & 0 & $6(21)$ \\
\hline
\end{tabular}

a'Treatment-related' indicates that the adverse event has been related to PF-03084014 and/or docetaxel.

${ }^{b}$ Three patients developed grade 3 pneumonia, and one patient each experienced aspartate aminotransferase elevation, dehydration, hyponatremia, colitis, hypokalemia, prolonged prothrombin time, and decreased performance status (all grade 3). One grade 5 treatment-related adverse event (septic shock) was reported in a patient who received PF-03084014 $150 \mathrm{mg}$ $\mathrm{BID} /$ docetaxel $75 \mathrm{mg} / \mathrm{m}^{2}$.

'Includes neutropenia and decreased neutrophil count.

${ }^{\mathrm{d} I n c l u d e s ~ l e u k o p e n i a}$ and decreased white blood cell count.

'Includes rash, erythematous rash, maculopapular rash, acne, and dermatitis acneiform.

fncludes thrombocytopenia and decreased platelet count.

$03084014100 \mathrm{mg}$ twice daily [BID]/docetaxel $75 \mathrm{mg} / \mathrm{m}^{2}$ ), three at dose $3 \mathrm{a}$ (PF-03084014 $100 \mathrm{mg}$ BID/docetaxel 100 $\left.\mathrm{mg} / \mathrm{m}^{2}\right)$, and 11 at dose $3 \mathrm{~b}(\mathrm{PF}-03084014150 \mathrm{mg} \mathrm{BID} /$ docetaxel $75 \mathrm{mg} / \mathrm{m}^{2}$ ) (Supplemental Table S1 and Table S2). Seven additional patients with $\mathrm{mTNBC}$ were treated in first-line at dose $2 \mathrm{~b}$ (estimated MTD) in the expansion phase. All treated patients $(N=29)$ were evaluable for safety, and 25 were evaluable for objective response.

Patient baseline demographic and disease characteristics are presented in Table 1. The majority of patients had ECOG performance status $0(62 \%)$ and metastatic disease $(86 \%)$, and received combination study treatment as first-line therapy (69\%) in the advanced/ metastatic setting.

\section{Dose-limiting toxicity (DLT) and safety profile}

Patients received treatment according to the study design [16] (Supplemental Information). Of 22 DLTevaluable patients, one (13\%) patient at dose $2 \mathrm{~b}$, one (33\%) patient at dose $3 \mathrm{a}$, and four $(36 \%)$ patients at dose $3 \mathrm{~b}$ experienced DLTs, including grade 3 diarrhea (dose $2 \mathrm{~b}$ ); grade 3 diarrhea (dose $3 \mathrm{a}$ ); and grade 3 dehydration, grade 3 nausea, grade 4 febrile neutropenia, and grade
5 septic shock (dose 3b) (Supplemental Table S2). All grade 3-4 DLTs resolved following dose reduction of PF-03084014 and docetaxel. Only three patients were treated at dose $3 \mathrm{a}$ due to concerns related to potential toxicity of treatment with docetaxel $100 \mathrm{mg}$. The patient, who died of septic shock at dose $3 \mathrm{~b}$, had developed grade 4 neutropenia 7 days after starting study combination treatment, indicating an event potentially related to docetaxel-induced bone marrow toxicity. A second, non-treatment-related death was reported at dose $2 \mathrm{~b}$ in a 67-year-old patient who experienced respiratory distress and fatal disease progression. The MTD for the combination, defined as the highest tested dose level with a DLT rate $<0.33$, was estimated to be PF-03084014 100 $\mathrm{mg} \mathrm{BID} /$ docetaxel $75 \mathrm{mg} / \mathrm{m}^{2}$ based on the DLTs observed at each dose level.

The most common all-grade, treatment-related adverse events (AEs) for the combination of PF03084014 with docetaxel reported in all patients $(N$ = 29) were neutropenia $(90 \%)$, fatigue $(79 \%)$, nausea $(72 \%)$, leukopenia $(69 \%)$, diarrhea $(59 \%)$, alopecia (55\%), anemia (55\%), and vomiting (48\%) (Table 2). PF$03084014 /$ docetaxel combination treatment-related grade 3-4 neutropenia was observed in $25(86 \%)$ patients, grade 
A

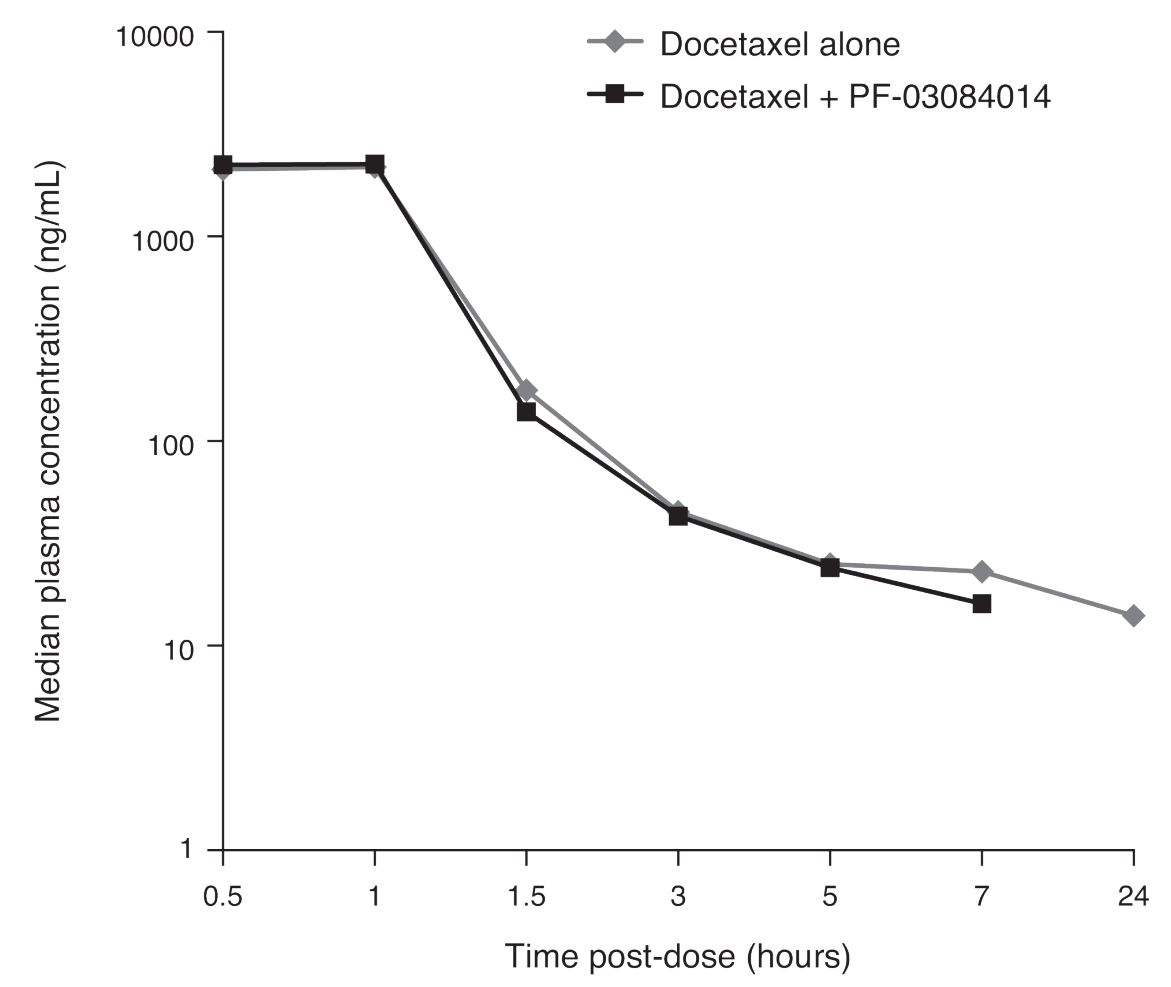

B

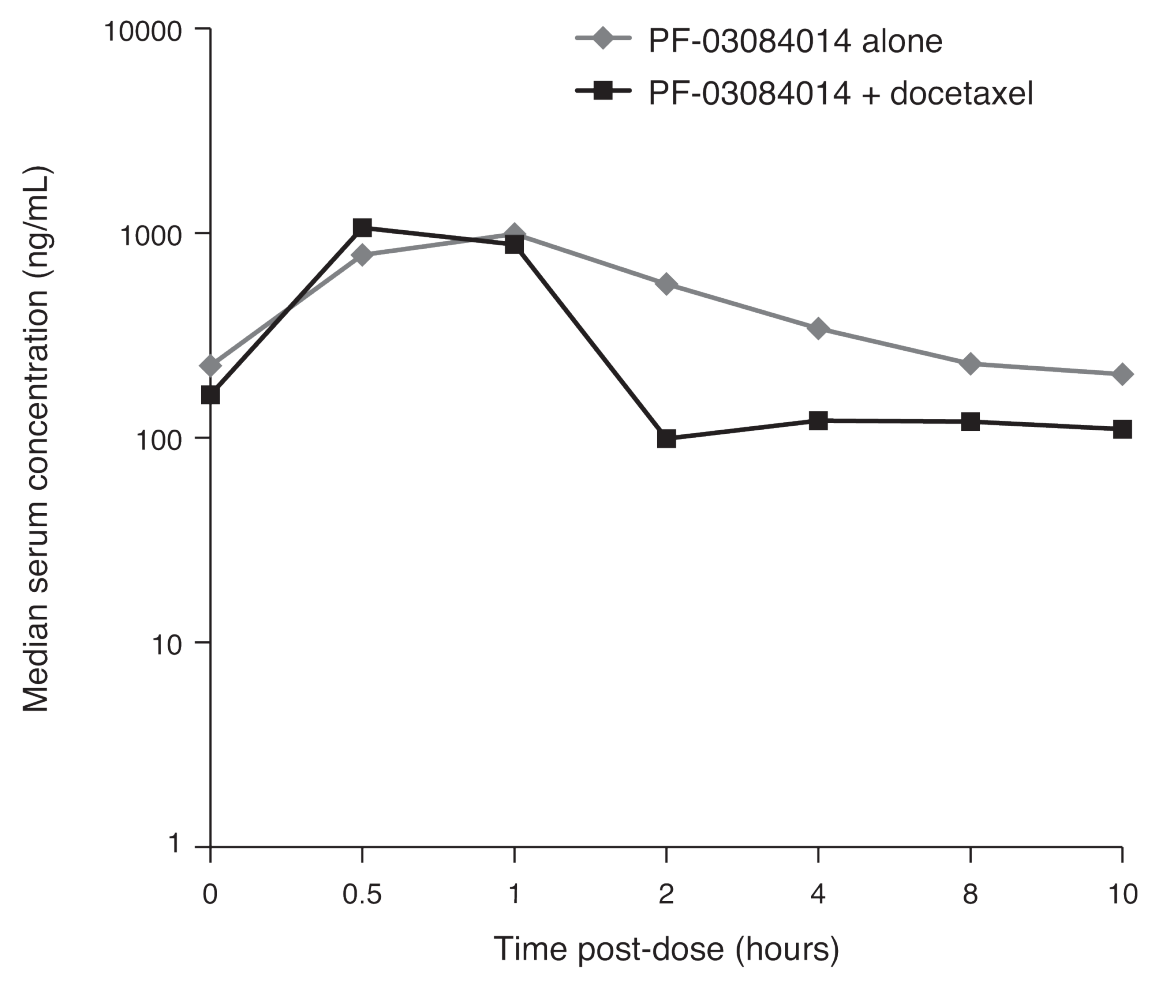

Figure 1: Median concentration-time profiles for docetaxel A. and PF-03084014 B. 
3-4 leukopenia in $19(66 \%)$ patients, and grade 3-4 febrile neutropenia in eight $(28 \%)$ patients; no treatment-related grade $\geq 3$ thrombocytopenia was reported. Other grade 3-4 combination treatment-related AEs noted included fatigue, nausea, diarrhea, anemia, vomiting, mucosal inflammation, and hypophosphatemia (Table 2). At the MTD, the most frequently reported non-hematologic grade 3-4 laboratory abnormalities were hypophosphatemia (33\%) and hypokalemia (13\%).

The majority (72\%) of patients discontinued PF03084014 due to disease progression. Four patients permanently discontinued PF-03084014 owing to a treatment-related AE: one patient (dose 3a) due to grade 3 vomiting and three patients (dose $3 \mathrm{~b}$ ) due to grade 2 fatigue, grade 3 pneumonia, and grade 4 febrile neutropenia ( $n=1$ each). Overall, median duration of treatment was four (range, 1-12) cycles for all patients and four (range, 2-12) cycles at the MTD.

\section{Pharmacokinetics}

No effect was observed on the pharmacokinetics of docetaxel when administered in combination with PF03084014 (Figure 1A). Median serum concentration-time profiles of PF-03084014 alone or in combination with docetaxel, at the MTD, are shown in Figure 1B. A lower, transient exposure to PF-03084014 was observed on days in which it was dosed in combination with docetaxel. At the MTD, maximum mean observed serum concentration of PF-03084014 was $963 \mathrm{ng} / \mathrm{ml}$ when administered alone and $950 \mathrm{ng} / \mathrm{ml}$ in combination with docetaxel.

\section{Antitumor activity}

Best change in target lesions from baseline for each response-evaluable patient is shown in Figure 2A. Four (16\%; 95\% CI 4.5-36.1\%) of 25 response-evaluable patients achieved a confirmed partial response, with response duration as shown in Figure 2B. Two of these patients received the combination at the MTD, and one had been previously treated with paclitaxel in the adjuvant setting. Nine (36\%) patients had stable disease, including five patients with unconfirmed partial response. Eleven (44\%) patients had best overall response of progressive disease (Supplementary Table S3). In the expansion cohort, median PFS was 4.1 (95\% CI 1.3-8.1) months, with a 6-month PFS rate of $17.1 \%$ (95\% CI 0.8-52.6\%).

\section{DISCUSSION}

We report here the results from the first phase I trial of the novel gamma-secretase inhibitor PF-03084014 in combination with docetaxel in patients with locally advanced or metastatic TNBC. Results from preclinical studies had demonstrated antitumor activity of this combination in xenograft models of TNBC [13].

Following dose escalation/de-escalation of either drug, the MTD for the combination in patients with TNBC was estimated to be PF-03084014 $100 \mathrm{mg}$ BID plus docetaxel $75 \mathrm{mg} / \mathrm{m}^{2}$. At the estimated MTD, combination treatment was generally well tolerated: one DLT, grade 3 diarrhea, was noted in one of the eight DLT-evaluable patients treated at this dose level. At higher doses, a patient in the PF-03084014 $150 \mathrm{mg}$ BID/docetaxel 75 $\mathrm{mg} / \mathrm{m}^{2}$ cohort $\mathrm{C}$ experienced grade 5 treatment-related septic shock, potentially related to docetaxel-induced neutropenia. The plasma exposure of docetaxel for this patient was greater than the mean exposure of the group. No unexpected toxicities were observed compared to results of prior studies conducted with single-agent PF03084014 in patients with solid tumors or hematologic malignancies [14, 15] or with docetaxel [1]. The most frequent treatment-related AEs reported for the combination of PF-03084014 and docetaxel across dose levels were neutropenia, fatigue, nausea, leukopenia, diarrhea, alopecia, anemia, and vomiting. The nonhematologic events were generally mild to moderate in severity with only grade 3 diarrhea reported frequently. Treatment with PF-03084014 in combination with docetaxel was not limited by severe diarrhea, as opposed to what was observed with other drugs from the same class, MK-0752 and RO4929097, administered as single agents $[17,18]$. In addition, development of squamous cell skin cancers was not observed after treatment with PF-03084014 either in combination with docetaxel or as a single agent [14].

No effect was observed in this study on the pharmacokinetics of docetaxel when administered in combination with PF-03084014. A transient decrease in exposure was noted for PF-03084014 during the days in which it was administered in combination with docetaxel. Prophylactic administration of dexamethasone from day -1 to 2 of each treatment cycle may potentially explain this lower exposure observed for PF-03084014 on the combination dosing day, resulting from an effect on metabolism and drug transport processes [19-21], but no clinical impact is foreseen because of continuous PF03084014 administration.

Four $(16 \%)$ patients had a confirmed partial response in first-line treatment of advanced disease; nine (36\%) patients achieved stable disease as best response, including five patients with unconfirmed partial response. The overall response rate observed in this study appears low, potentially reflecting the limited number of patients treated in first-line with the combination at the MTD. In addition, three of the patients treated in first-line at the estimated MTD had a dose reduction of PF-03084014 and/or docetaxel. Previous results of phase I studies conducted with the gamma-secretase inhibitor RO4929097 


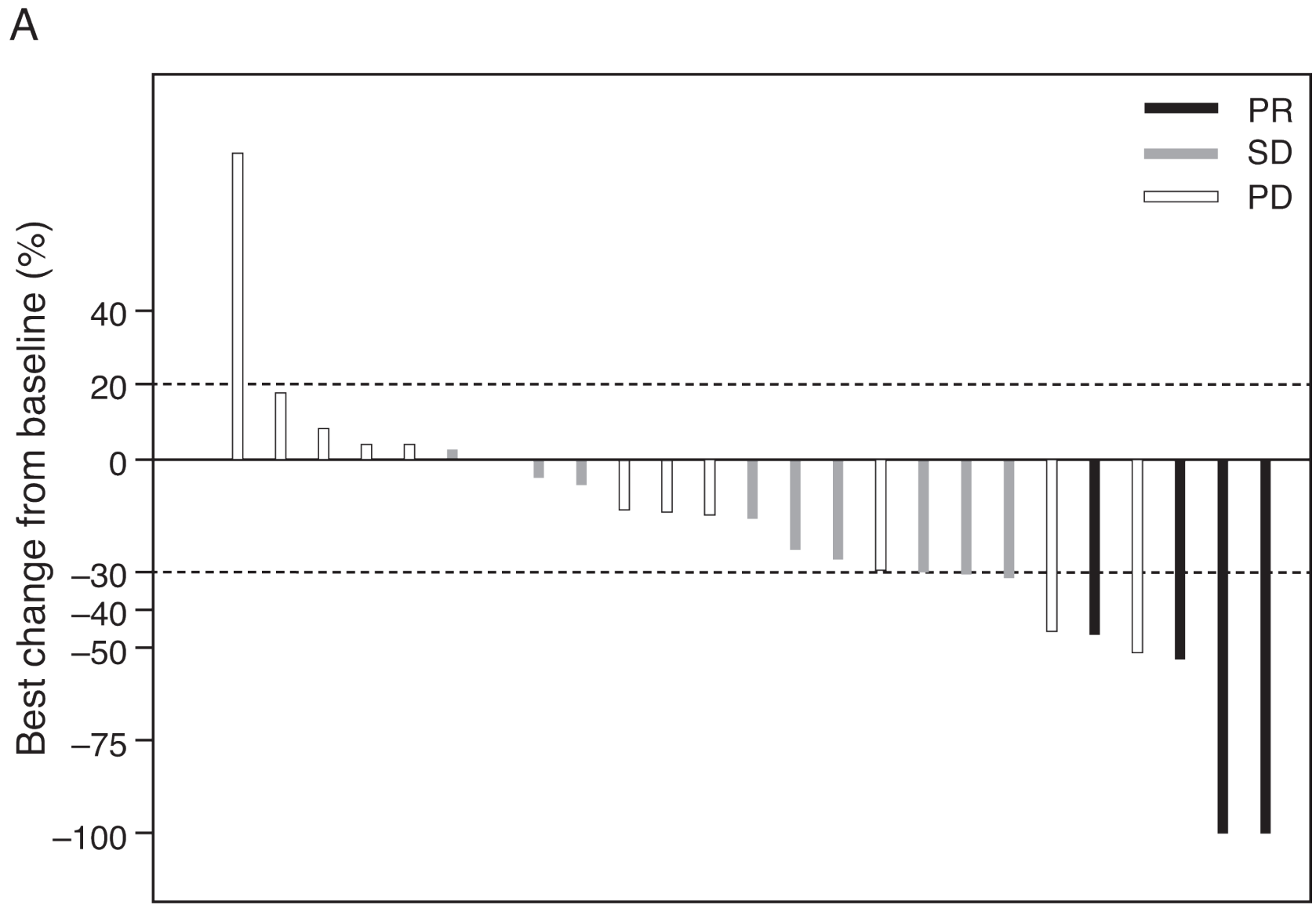

Evaluable patients

B

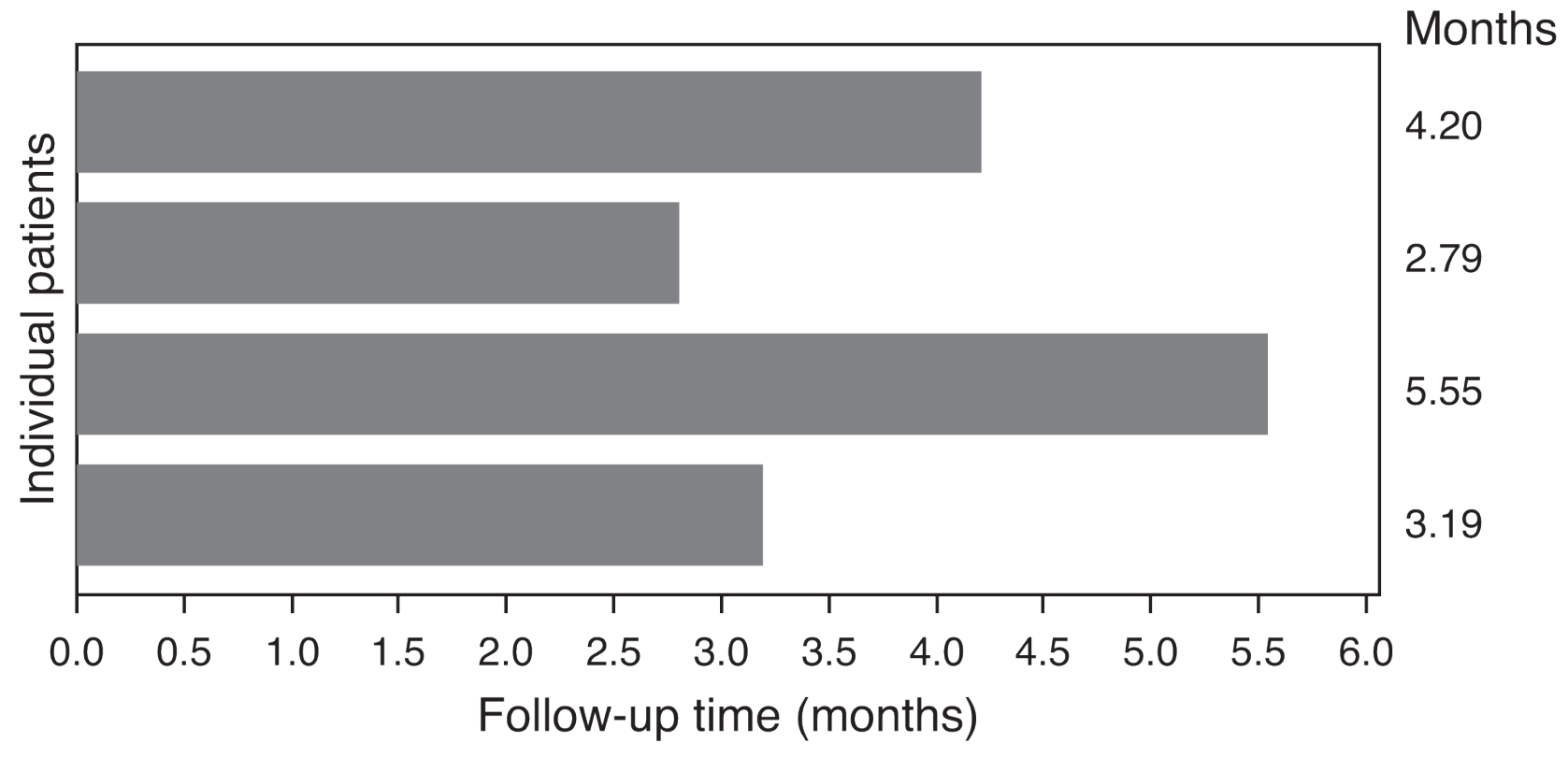

Figure 2: Best tumor size change from baseline A. Duration of response to treatment with PF-03084014 and docetaxel B. PR, partial response; $\mathrm{PD}$, progressive disease; $\mathrm{SD}$, stable. 
in combination with gemcitabine or capecitabine showed limited antitumor activity in patients with advanced solid malignancies [22, 23]. One (6\%) patient with nasopharyngeal cancer had a partial response following treatment with the RO4929097/gemcitabine combination at a dose above the recommended phase II dose [22]. Three $(10 \%)$ patients with colon or cervical cancer had a partial response to the RO4929097/capecitabine combination [23].

\section{CONCLUSIONS}

Treatment of patients with locally advanced or metastatic TNBC with the gamma-secretase inhibitor PF03084014 in combination with docetaxel demonstrated a manageable safety profile and limited preliminary antitumor activity. The MTD for the combination was estimated to be PF-03084014 $100 \mathrm{mg}$ BID/docetaxel 75 $\mathrm{mg} / \mathrm{m}^{2}$.

\section{PATIENTS AND METHODS}

\section{Study design and patients}

This phase Ib, open-label, multicenter study was conducted in patients with advanced TNBC and divided into two parts: (1) a dose-finding component in patients who had received up to two prior lines of chemotherapy for metastatic disease, and (2) an expansion cohort restricted to patients treated in the first-line, advanced setting at the estimated MTD.

Adult women with advanced/metastatic TNBC were eligible for the study if they had documented ERnegative, PR-negative, and HER2-negative status (doseescalation and expansion cohort) or were ER/PR-positive, HER2-negative, and were unresponsive to hormonal therapy by investigator assessment (dose-escalation). Further, eligible patients were required to have at least one measurable lesion by RECIST version 1.1 criteria, Eastern Cooperative Oncology Group (ECOG) performance status 0 or 1 ; and adequate renal, liver, and bone marrow function.

Patients were excluded if they had symptomatic brain metastases requiring steroids, had received systemic anticancer treatment within 3 weeks of study entry (6 months for taxanes), had been previously treated with a gamma-secretase inhibitor or NOTCH signaling inhibitor, had a corrected QT (QTc) interval > $470 \mathrm{msec}$, or had current use or anticipated need for treatment with moderate/strong cytochrome P450 (CYP) 3A4 inhibitors or strong CYP3A4 inducers. Further, patients who were candidates for resection or radiation therapy with curative intent were not eligible.

Approval was obtained from the ethics committees of the participating institutions. Patients gave written informed consent. The study (NCT01876251) followed the Declaration of Helsinki and the International Conference on Harmonization Good Clinical Practice guidelines.

The primary endpoint was first-cycle DLT attributable to PF-03084014 in combination with docetaxel for the dose-finding part of the study and PFS at 6 months for the expansion cohort. Hematologic DLT included grade 4 neutropenia lasting $>7$ days, febrile neutropenia, grade $\geq$ 3 neutropenic infection, grade $\geq 3$ thrombocytopenia with bleeding, and grade 4 thrombocytopenia without bleeding, if attributable to PF-03084014 in combination with docetaxel. Non-hematologic DLT included grade $\geq 3$ AEs if maximally treated; grade 3 QTc prolongation ( $>500$ $\mathrm{msec}$ ) persisting after correction of any reversible causes; dose delay of 2 weeks due to treatment-related AEs; and failure to deliver at least $80 \%$ of the planned dose in first cycle due to treatment-related AEs, if attributable to PF03084014 in combination with docetaxel. Secondary study endpoints were safety, objective response, duration of response, and pharmacokinetics of PF-03084014 in combination with docetaxel.

\section{Study treatment}

PF-03084014 was administered orally twice daily (BID) continuously in combination with docetaxel given intravenously on day 1 of each 21day cycle. Steroid premedication was given from day -1 to day 2 of each cycle, as required for docetaxel administration. Administration of PF-03084014 in the dose-finding component started on day 2 of cycle 1 for pharmacokinetics evaluation purposes. In the expansion cohort, patients received PF-03084014 and docetaxel at the estimated MTD starting on day 1 of each 21-day cycle, with no specific timing requirement for the administration of PF-03084014 relative to docetaxel. Study treatment was given until disease progression, patient withdrawal, or unacceptable toxicity. Treatment with granulocyte-colony stimulating factor (G-CSF) was allowed in patients with neutropenia. Prophylactic use of G-CSF was permitted only after cycle 1 .

\section{Study assessments}

AEs were continuously monitored and graded for severity using the National Cancer Institute Common Terminology Criteria for Adverse Events (CTCAE) version 3.0.

Antitumor activity was assessed by computed tomography or magnetic resonance imaging and bone scans at baseline, every 6 weeks, until disease progression or death, patient refusal, start of another anticancer treatment, or until 1 year from cycle 1 , day 1 , of last enrolled patient whichever occurred first, using RECIST version 1.1. 
Blood samples to determine the pharmacokinetics of PF-03084014 were collected on days 2, 8, and 21 (days 1 and 21 in the expansion cohort) of cycle 1 , and on day 1 of subsequent cycles. In the dose-finding component, blood samples were collected on day 1 of cycles 1 and 2 to evaluate the pharmacokinetics of docetaxel. Samples were analyzed for PF-03084014 and docetaxel concentrations using validated analytical methods.

\section{Statistical methods}

Dose escalation/de-escalation followed a $2 \times 3$ matrix design with the modified toxicity probability interval method [16] (mTPI, see Supplemental Methods) using doses of PF-03084014 and docetaxel shown in Supplemental Table S1. The estimated MTD was defined as the highest tested dose level with estimated DLT rate $<0.33$.

The objective response rate was summarized with exact two-sided $95 \%$ confidence interval (CI) calculated using a method based on the $\mathrm{F}$ distribution. PFS was summarized by the Kaplan-Meier method with $95 \%$ CI for the median calculated using the Brookmeier-Crowley method.

\section{ACKNOWLEDGMENTS AND FUNDING}

The authors thank all participating patients and their families, as well as the global network of investigators, research nurses, study coordinators, and operations staff. This study was sponsored by Pfizer. Medical writing and editorial support was provided by $\mathrm{S}$. Mariani, $\mathrm{MD}, \mathrm{PhD}$, of Engage Scientific Solutions, and was funded by Pfizer. Trial Registration Number: NCT01876251.

European Clinical Trial Database (EudraCT) Number: 2013-000659-41

\section{CONFLICTS OF INTEREST}

Drs. G. Curigliano, M. Locatelli, and D. Aftimos have nothing to disclose. Dr. P. LoRusso received research funding from Pfizer. Dr. A. Awada received consulting honoraria from Bayer, Eisai, and Roche. Dr. E. C. Dees received research funding from Agensys, Aveo, Genentech/Roche, GSK, Millennium, and Novartis; and consulting honoraria from Novartis. Dr. M. Pegram received consulting honoraria from Genentech/Roche, Novartis, and Pfizer; and expert testimony honoraria from Novartis. Drs. B. Huang, R. Cesari, Y. Jiang, M. N. Shaik, and K. A. Kern were full-time employees of Pfizer during the conduct of this study.

\section{REFERENCES}

1. Anders CK, Zagar TM, Carey LA. The management of early-stage and metastatic triple-negative breast cancer. Hematol Oncol Clin North Am. 2013; 27:737-749.

2. Foulkes WD, Smith IE, Reis-Filho JS. Triple-negative breast cancer. N Engl J Med. 2010; 363:1938-1948.

3. Prat A, Lluch A, Albanell J, Barry WT, Fan C, Chacón JI, Parker JS, Calvo L, Plazaola A, Arcusa A, Seguí-Palmer MA, Burgues O, Ribelles N, et al. Predicting response and survival in chemotherapy-treated triple-negative breast cancer. Br J Cancer. 2014; 111:1532-1541.

4. Lehmann BD, Bauer JA, Chen X, Sanders ME, Chakravarthy AB, Shyr Y, Pietenpol JA. Identification of human triple-negative breast cancer subtypes and preclinical models for selection of targeted therapies. J Clin Invest. 2011; 121:2750-2767.

5. Gupta PB, Onder TT, Jiang G, Tao K, Kuperwasser C, Weinberg RA, Lander ES. Identification of selective inhibitors of cancer stem cells by high-throughput screening. Cell. 2009; 138:645-659.

6. Gupta PB, Chaffer CL, Weinberg RA. Cancer stem cells: mirage or reality? Nat Med. 2009; 15:1010-1012.

7. Lee CW, Raskett CM, Prudovsky I, Altieri DC. Molecular dependence of estrogen receptor-negative breast cancer on a notch-survivin signaling axis. Cancer Res. 2008; 68:52735281.

8. Yamaguchi N, Oyama T, Ito E, Satoh H, Azuma S, Hayashi M, Shimizu K, Honma R, Yanagisawa Y, Nishikawa A, Kawamura M, Imai Ji, Ohwada S, et al. NOTCH3 signaling pathway plays crucial roles in the proliferation of ErbB2negative human breast cancer cells. Cancer Res. 2008; 68:1881-1888.

9. Reedijk M. High-level coexpression of JAG1 and NOTCH1 is observed in human breast cancer and is associated with poor overall survival. Cancer Res. 2005; 65:8530-8537.

10. Izrailit J, Reedijk M. Developmental pathways in breast cancer and breast tumor-initiating cells: Therapeutic implications. Cancer Lett. 2012; 317:115-126.

11. Qiu M, Peng Q, Jiang I, Carroll C, Han G, Rymer I, Lippincott J, Zachwieja J, Gajiwala K, Kraynov E, Thibault S, Stone D, Gao Y, et al. Specific inhibition of Notch1 signaling enhances the antitumor efficacy of chemotherapy in triple negative breast cancer through reduction of cancer stem cells. Cancer Lett. 2013; 328:261-270.

12. Zhang CC, Pavlicek A, Zhang Q, Lira ME, Painter CL, Yan Z, Zheng X, Lee NV, Ozeck M, Qiu M, Zong Q, Lappin PB, Wong A, et al. Biomarker and pharmacologic evaluation of the $\gamma$-secretase inhibitor PF-03084014 in breast cancer models. Clin Cancer Res. 2012; 18:5008-5019.

13. Zhang CC, Yan Z, Zong Q, Fang DD, Painter C, Zhang Q, Chen E, Lira ME, John-Baptiste A, Christensen JG. Synergistic effect of the $\gamma$-secretase inhibitor PF-03084014 
and docetaxel in breast cancer models. Stem Cells Transl Med. 2013; 2:233-242.

14. Messersmith WA, Shapiro GI, Cleary JM, Jimeno A, Dasari A, Huang B, Shaik MN, Cesari R, Zheng X, Reynolds JM, English PA, McLachlan KR, Kern KA, et al. A phase I, dose-finding study in patients with advanced solid malignancies of the oral $\gamma$-secretase inhibitor PF-03084014. Clin Cancer Res. 2014; 21:60-67.

15. Papayannidis C, DeAngelo DJ, Stock W, Huang B, Shaik MN, Cesari R, Zheng X, Reynolds JM, English PA, Ozeck M, Aster JC, Kuo F, Huang D, et al. A phase 1 study of the novel gamma-secretase inhibitor PF-03084014 in patients with T-cell acute lymphoblastic leukemia and T-cell lymphoblastic lymphoma. Blood Cancer J. 2015; 5:e350.

16. Huang B, Bycott P, Talukder E. Novel dose-finding designs and considerations on practical implementations in oncology clinical trials. J Biopharm Stat. 2016; Feb 16:112.

17. Krop I, Demuth T, Wen PY, Wen PY, Mason WP, Chinnaiyan P, Butowski N, Groves MD, Kesari S, Freedman SJ, Blackman S, Watters J, Loboda A, et al. Phase I pharmacologic and pharmacodynamic study of the gamma secretase (Notch) inhibitor MK-0752 in adult patients with advanced solid tumors. J Clin Oncol. 2012; 30:2307-2317.

18. Tolcher AW, Messersmith WA, Mikulski SM, Papadopoulos KP, Kawak EL, Gibbon DG, Patnaik A, Falchook GS, Dasari A, Shapiro GI, Boylan JF, Xu ZX, Wang K, et al. Phase I study of R04929097, a gamma secretase inhibitor of Notch signaling, in patients with refractory metastatic or locally advanced solid tumors. J Clin Oncol. 2012; 30:2348-2353.
19. Hilli J, Sailas L, Jyrkkiö S, Pyrhönen S, Laine K. NCT01110291: induction of CYP3A activity and lowered exposure to docetaxel in patients with primary breast cancer. Cancer Chemother Pharmacol. 2010; 67:1353-1362.

20. Iwanaga K, Honjo T, Miyazaki M, Kakemi M. Timedependent changes in hepatic and intestinal induction of cytochrome P450 3A after administration of dexamethasone to rats. Xenobiotica. 2013; 43:765-773.

21. Yumoto R, Murakami T, Sanemasa M, Nasu R, Nagai J, Takano M. Pharmacokinetic interaction of cytochrome P450 3A-related compounds with rhodamine 123, a P-glycoprotein substrate, in rats pretreated with dexamethasone. Drug Metab Dispos. 2001; 29:145-151.

22. Richter S, Bedard PL, Chen EX, Clarke BA, Tran B, Hotte SJ, Stathis A, Hirte HW, Razak ARA, Reedijk M, Chen Z, Cohen B, Zhang W-J, et al. A phase I study of the oral gamma secretase inhibitor R04929097 in combination with gemcitabine in patients with advanced solid tumors (PHL078/CTEP 8575). Invest New Drugs. 2013; 32:243-249.

23. LoConte NK, Razak ARA, Ivy P, Tevaarwerk A, Leverence R, Kolesar J, Siu L, Lubner SJ, Mulkerin DL, Schelman WR, Deming DA, Holen KD, Carmichael L, et al. A multicenter phase 1 study of $\gamma$-secretase inhibitor RO4929097 in combination with capecitabine in refractory solid tumors. Invest New Drugs. 2014; 33:169-176. 